\title{
Medieval origins of modern weather forecasting
}

Article

Accepted Version

Lawrence-Mathers, A. ORCID: https://orcid.org/0000-00016216-624X (2021) Medieval origins of modern weather forecasting. Weather, 76 (5). pp. 144-147. ISSN 0043-1656 doi: https://doi.org/10.1002/wea.3917 Available at https://centaur.reading.ac.uk/96365/

It is advisable to refer to the publisher's version if you intend to cite from the work. See Guidance on citing.

To link to this article DOI: http://dx.doi.org/10.1002/wea.3917

Publisher: Wiley

All outputs in CentAUR are protected by Intellectual Property Rights law, including copyright law. Copyright and IPR is retained by the creators or other copyright holders. Terms and conditions for use of this material are defined in the End User Agreement.

\section{www.reading.ac.uk/centaur}

\section{CentAUR}

Central Archive at the University of Reading

Reading's research outputs online 


\section{Medieval Origins of Modern Weather Forecasting}

Even in the twenty-first century forecasting the weather can be challenging, while public expectations of accuracy are high. However, for the UK public at least, complaining about terrible weather or the inaccuracy of forecasts does provide a familiar topic of conversation. Weather forecasts are now well-established as part of the daily news cycle. It is also well known that they began, along with modern meteorology, in the nineteenth century, and that daily forecasts first appeared in The Times (of London) in August 1861. The term itself was created by one of the founders of this new type of weather prediction, Robert FitzRoy, who strongly believed that forecasts should be published as a public service - even if it led to ridicule for him, personally. Following his appointment as Superintendent of the Meteorological Department of the Board of Trade in 1854 FitzRoy established 15 coastal observation stations, and was able also to use the new technology of the telegraph to make the reception and collation of weather observations very much faster [Eden, 2009]. It was in October 1860 that he received the first such telegraph from the Valentia Observatory on the SW coast of Ireland; and from 1861 until his death in 1865 he made it his responsibility to issue not only reports but also warnings of impending weather. FitzRoy's intention in coining the new term was to make it clear that his 'forecasts' used a scientific procedure, based on reliable data collection, and had nothing to do with the 'prognostications' then published annually in cheap almanacs.

These almanacs were issued by astrologers and were increasingly derided by 1800 . They have also been excluded from histories of early-modern meteorology on the grounds that they were not based on scholastic commentaries on Aristotle's work [Martin, 2011]. However, some authors made 'modern' arguments for their long-established methods. A very popular title was Vox Stellarum which was issued by the Stationers' Company from 1700 and continued to be credited to Francis Moore throughout much of the nineteenth century (making his appellation of 'Old Moore' very appropriate). By 1804 the author was already competing with newer methods of predicting the weather and was proudly quoting monthly measurements of rainfall in the previous year, 'taken at the Royal Society's House in London'. The number of places for which monthly measurements of rainfall were given grew considerably over the next decades, and attention was also given to atmospheric pressure. The compiler combined analysis of this data with his astrological prognostications, to produce brave predictions of the timing and quantity of rainfall. He urged that if 'journals of the weather' were kept across the kingdom, and published annually, 'this in Time would tend to bring Meteorology to greater Perfection'. By 1848 his readers were also urged to use a barometer, in order to increase meteorological knowledge and prove the efficacy of traditional prognostication. Hindsight makes it clear that it was FitzRoy's approach that deservedly prevailed; but attempts to combine scientific method and astrological belief have a very long, and influential, history.

Fig. 1 Vox Stellarum 1804; opening for January. (Almanac and photo: author's own)

Medieval astronomer/astrologers already produced forecasts using both detailed observations of actual weather and complex astronomical and mathematical calculations. My research [LawrenceMathers, 2019] has shown that these methods were taken seriously from the 9th to the 18th centuries. In the 16th and 17th centuries the astronomers Tycho Brahe and Johannes Kepler still made forecasts of this sort and still recommended the collection of data to improve accuracy. The 
scientific theory involved started with classical astronomy, which espoused the idea that celestial bodies - especially planets - exerted powerful forces over the Earth and its inhabitants. Each planet was believed to have a specific set of qualities and powers, which affected related phenomena on Earth. Exactly how this worked was elaborated by natural philosophers in the Islamicate world, drawing upon the work of classical Greek, Hellenistic, Persian and Indian authorities. The Aristotelian model of the universe, with the Earth stationary at its centre, was accepted almost universally, even though some Arabian astronomers posited that the Earth rotated on its axis, and others took up suggestions that Mercury and Venus actually orbited around the Sun.

Fig. 2 Leiden, Universiteitsbibliotheek, MS VLQ, f93v. Positions of the planets at Easter, 816; in a copy of Aratus' Phaenomena made for the court of Louis the Pious (Emperor 814-40). The Earth is at the centre of the image, with the Sun on the left and next to the ram of Aries. Mercury and Venus are circling the Sun as it moves around the Earth. [Image: public domain]

Islamicate scientists hypothesised that the Earth was surrounded by spheres composed of the four classical elements (earth, water, air and fire) which were in turn surrounded by the spheres within which the planets were carried. Both the planets and the stars emitted rays which reached the Earth's surface, and which interacted with one another and with the elemental spheres en route.

Perhaps most influential were the arguments of the great philosopher-scientist, al-Kindi (c800-c870 CE) [Burnett, 2004]. He accepted the theory that the movements of the celestial bodies generated heat, which in turn created movement and change in the atmospheric zone around the Earth. In addition, he argued that it was the effects of the planetary rays which determined in detail how meteorological phenomena would fluctuate on Earth. The qualities and elemental affinities attributed to each planet since Antiquity were accepted, so that Saturn, for instance, was especially associated with the element of earth, and was dry and cold. Its rays would thus carry these attributes. Most powerful in this system were the Sun and the Moon, whose effects on phenomena such as season, climate, daylight, tides and (allegedly) bodily fluids and plant growth were known to all educated individuals. These greater luminaries were powerful enough to have major effects on the rays of the other planets but could in turn be affected when other planets were in influential positions in relation to them.

Fig. 3 Bodleian Library, University of Oxford, Ms Ashmole 370, f25r. A volvelle composed of rotating dials, for calculating the positions and aspects of the Sun and Moon (together with the time by day and night, the elevation of the Sun at noon, and the length of daylight) for any day in the year.

This theory had already been given mathematical and geometrical precision by Claudius Ptolemy of Alexandria, the great geographer, cosmologist and astronomer of the 2 nd century. Ptolemy's main contribution was to produce complex models which made it possible to predict with considerable accuracy where the planets would be on any chosen date [Ptolemy, Almagest, 1998 ed]. This in turn meant, as Ptolemy said, that it was possible to calculate how their effects would interact, and what the outcome would be for the Earth's atmosphere and weather. Ptolemy outlined how detailed weather forecasts could be made, through interpreting the calculated positions of all the significant celestial bodies on the chosen date, in relation to one another and to a specified point on the earth's surface [Ptolemy, Tetrabiblos, 1940 ed.]. The standard method for recording the positions was in degrees and minutes of longitude on the ecliptic, described in terms of the twelve equal divisions of the circle of the zodiac. This was important since these divisions (known as houses or signs) had 
characteristics largely determined by the stars in or close to them, and these would affect nearby planets.

Fig 4 University of Reading, Special Collections, MS 2087, f3r. This calendar-folio in a fifteenth-century book of hours shows the first half of the month of April. The ram, symbol of the zodiac sign of Aries (through which the Sun moves from the Spring equinox until late April) is in the lozenge at the bottom. The roundel on the right depicts the seasonal weather expected in this month.

To quantify the interactions between planets it was also necessary to note the angular relationships between the houses they occupied, and whether they were moving towards or away from one another. The latter was especially important when considering interactions involving the powerful and fast-moving Moon. Ptolemy's summary of the theory was: 'It is clear that when the planets are in significant associations with one another they produce very many variations in the quality of our atmosphere, with the intrinsic power of each remaining but being modified in its strength by the forces of the bodies with which it is configured' [Tetrabiblos, p.45]. Thus, an apparently simple model could generate a relatively large quantity of data when it came to producing an actual forecast.

Philosopher-scientists in the Arab Empire from the 9th century onwards compiled new data into updated planetary tables and refined Ptolemy's methods of weather forecasting. Their work was slowly assimilated by scholars in Europe from the late 11th century and incorporated into university teaching of astronomy by the 13th century. The main barrier to wider successful forecasting was the complexity of the calculations involved, but advances in mathematics and the adoption of HinduArabic numerals helped to overcome this. Also important was the rise of acclaimed experts in the new 'science of the stars' who achieved fame for successful predictions and forecasts and rose to influential positions in both political centres and universities. The spread of Latin translations made al-Kindi one such expert, and his overview of how the atmosphere and the weather worked, and the causes of heat and cold, drought and rain, and wind remained influential well into the sixteenth century. He was unusual in challenging Aristotle's views on some of these phenomena, and particularly on the winds. Whilst 'the Philosopher' related the winds to 'exhalations' occurring above and below the surface of the earth, al-Kindi preferred heat as the fundamental driving force. He stated that the joint influence of the Sun and Moon determined the level of heat in the air of a particular region, and that heated air would rapidly expand into a zone where cooler air had contracted, thus determining the strength and direction of the wind [Lawrence-Mathers, 82-4].

Fig 5 This fourteenth-century English astrolabe is modelled on those produced for Islamicate astronomers. Such devices provided maps of the sky as seen from chosen latitudes and facilitated the calculation of planetary longitudes. Image copyright Oxford Museum of History of Science.

One of the most popular Latin treatises on weather forecasting was attributed to Robert Grosseteste, the 13th-century scientist and bishop of Lincoln. This offered a simplified method of making the forecasts and urged that forewarning of droughts or floods would save many lives. Later, some practitioners achieved great fame for their forecasts. The Oxford astronomer/astrologer, John of Eschenden, was praised for having predicted the great plague of $1348 / 9$, though his prediction was in fact rather vague. His ongoing prognostications of prolonged cold, wet and windy weather, causing floods and famines into the 1370s, were also acclaimed as correct. It should be noted that the concept of planetary influence on material phenomena, including the atmosphere and its 
movements, raised no theological problems for the medieval Church. Meteorological study and weather prognostication were entirely acceptable areas of study.

Fig 6 Grosseteste's chart for the compilation and analysis of astrometeorological data. Bodleian Library, University of Oxford, Ms.Bodl 464, f125r.

The serious work going into weather forecasting in the late Middle Ages is further shown by the growing practice of making detailed observations of weather and correlating them with forecasts. The earliest known examples of this come from England and Germany. Perhaps earliest of all are the weather notes entered into the margins of a calendar for 1269/70, found in a collection of the works of Roger Bacon which was put together in Oxford in the late thirteenth century. A full translation was published [in Weather, 29:6 (1974)] and the juxtaposition was then seen as puzzling. In the light of Bacon's arguments that astronomers, like all other scientists, should put their models 'to the test of experience' in order to improve their utility, the concept of comparing planetary positions with actual weather seems consistent with Bacon's drive to establish the sciences (including what would now be classed as astrology) as of fundamental value for society.

Fig 7 BL Ms Royal 7 F VIII, f.178v. Calendar, planetary positions and weather records for January 1269.

Similar work was taken seriously in the fourteenth century, as is shown by the weather observations compiled and studied alongside planetary data in Oxford, Lincoln, Wurzburg and (possibly) Basel. Records for 1337-44 accompany the 'Rules' for weather forecasting issued by Master William de Merle, who was linked to Merton College, Oxford, and to William Reed (bishop of Chichester, 136985) [Symons, 1891]. In the Basel manuscript, records of weather in the years 1399-1406 are found with notes on astrometeorological factors which possibly correlated with them. For instance, in 1400 April 7 was cloudy, with short sunny intervals and a strong West wind. It is noted that the Moon moved away from the beneficent planet, Jupiter, and out of an Air sign, whilst approaching Mercury, known to cause disturbance in the air. The effect of such empirical study, however surprisingly, was to increase confidence in astronomically based weather forecasting. Arguably, the idea that the route to reliable forecasts was via the collection of records, analysed alongside meteorological models, was a major legacy of medieval science in this field.

Such forecasting was made more accessible by the production, starting in the fourteenth century, of calendars and ephemerides which gave pre-calculated planetary positions over long runs of years, for stated regions. The arrival of print technology in the fifteenth century made it possible for the calculations of astronomers like Regiomontanus (1436-76) to reach large numbers of users. Regiomontanus himself was an expert weather forecaster, and included his own rules in his Almanac, as well as an outline of 'Weather forecasting according to al-Kindi'. By Regiomontanus' time it was an established requirement that the holders of university chairs in astronomy/astrology should produce annual prognostications, including weather forecasts, for the great and the good in their cities. Many of these were rushed into print and served as models for the popular almanacs which were produced in impressively high numbers from the sixteenth century onwards. Astronomers such as Brahe and Kepler continued this medieval method of weather forecasting. Brahe argued for making both weather records and predictions, with the aim of increasing the accuracy of the forecasts by using more evidence [Tycho Brahe, 1573; 1901 ed.]; and weather observations and prognostications made by Kepler from 1593-1624 survive. With such support, the 
demand for almanacs is not surprising. The more expensive ones provided daily weather forecasts for the coming year, in phraseology still echoed by modern forecasters. Winds were 'variable' or 'fierce', rain was 'drizling', 'driving' or 'showerie', and good weather was 'fair'.

Fig 8 Buckminster's Almanac and Prognostication for 1590, opening for October. University of Reading, Special Collections.

Indeed, one effect of the popularity of weather prognostications in the almanacs was the creation of a vocabulary of weather-types. Key terms in English are already visible in the 1590 almanac shown above. By 1700 the term 'overcast' was in use, while cold and frost were still described as 'sharp' and the descriptor 'unsettled' had appeared, as had the promise that showers would 'clear quickly'. Writing at the end of an unsettled August it is striking to see that August 1709 was predicted to be rather similar. The almanac Merlinus Liberatus warned that late August would be a season of storms, while September would see 'brisk winds' and 'unsettled' conditions. The author discussed details of the wet summers of 1648,1672,1673, 1692 and 1708, and suggested that 'those that have journals of the weather by them may make further observations'. Some of Dove's predictions for the same year would not sound entirely out of place in a modern forecast, since part of April was to be 'cloudy, with rain in several places', August has 'showers, but soon clearing' and September was to bring 'wind and driving rain'.

It is this combination of an established language for forecasting and an emphasis on the importance of making records of actual weather that constitutes the most lasting legacy of medieval meteorology. The evidence presented here has shown that, by 1800 , the idea that accurate recording of weather would increase the accuracy of forecasting was already five hundred years old. A learned discourse for describing the weather in English came rather later, but still underlies the language of contemporary forecasters.

\section{References}

Brahe, T., De Nova Stella; 1573, Ed. Regia Societas Scientiarium Danica, 1901

Burnett, C., 'Weather Forecasting in the Arabic World', in E. Savage-Smith, Ed., Magic and Divination in Early Islam, Ashgate, Aldershot and Burlington, 2004, pp. 201-10.

Eden, P., 'Traditional weather observing in the UK: An historical overview', Weather, Vol.64, No 9, Sept. 2009, pp. 239-45.

Lawrence-Mathers, A.E., Medieval Meteorology; Forecasting the Weather from Aristotle to the Almanac, Cambridge University Press, 2019

Martin, C., Renaissance Meteorology: Pomponazzi to Descartes, Baltimore, Johns Hopkins University Press, 2011

Ptolemy, Almagest, Trans. G.J. Toomer, Foreword O. Gingerich, Princeton University Press, Princeton N.J., 1998

Ptolemy, Tetrabiblos, Ed. And Trans. F.E. Robbins, Harvard University Press, Camb. Mass., 1940

Symons, G.J., Ed., Merle's MS. Consideraciones temperiei pro 7 annis Per Magistrum Willelmum Merle, Socium Domus de Merton: The earliest known journal of the weather: kept by the Rev. William 
Merle, Rector of Driby, Lincolnshire, 1337-1344, London, 1891 (printed for Symons by Stanford, London)

\section{[All images are copyright unless otherwise stated]}

Fig 1

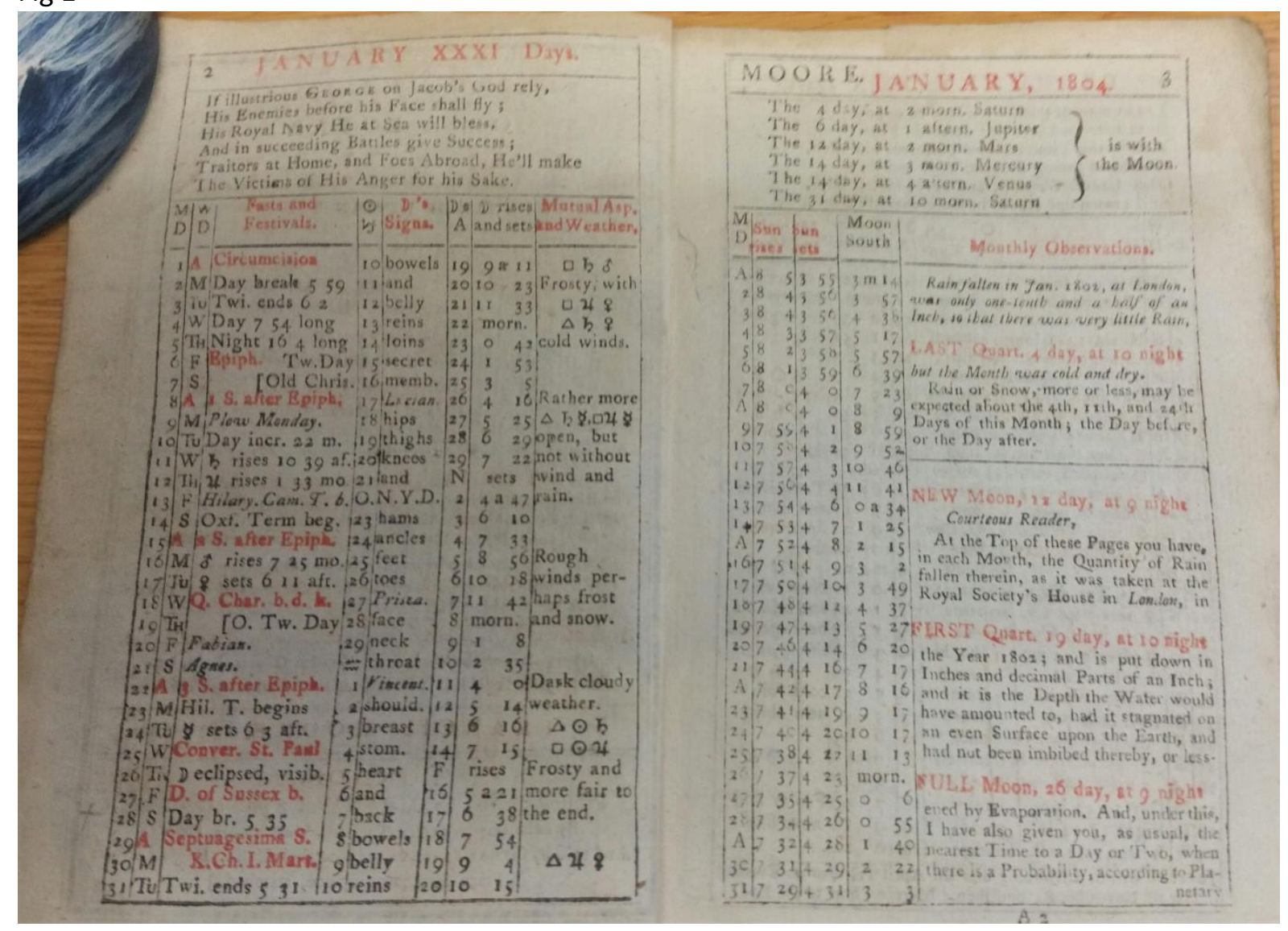




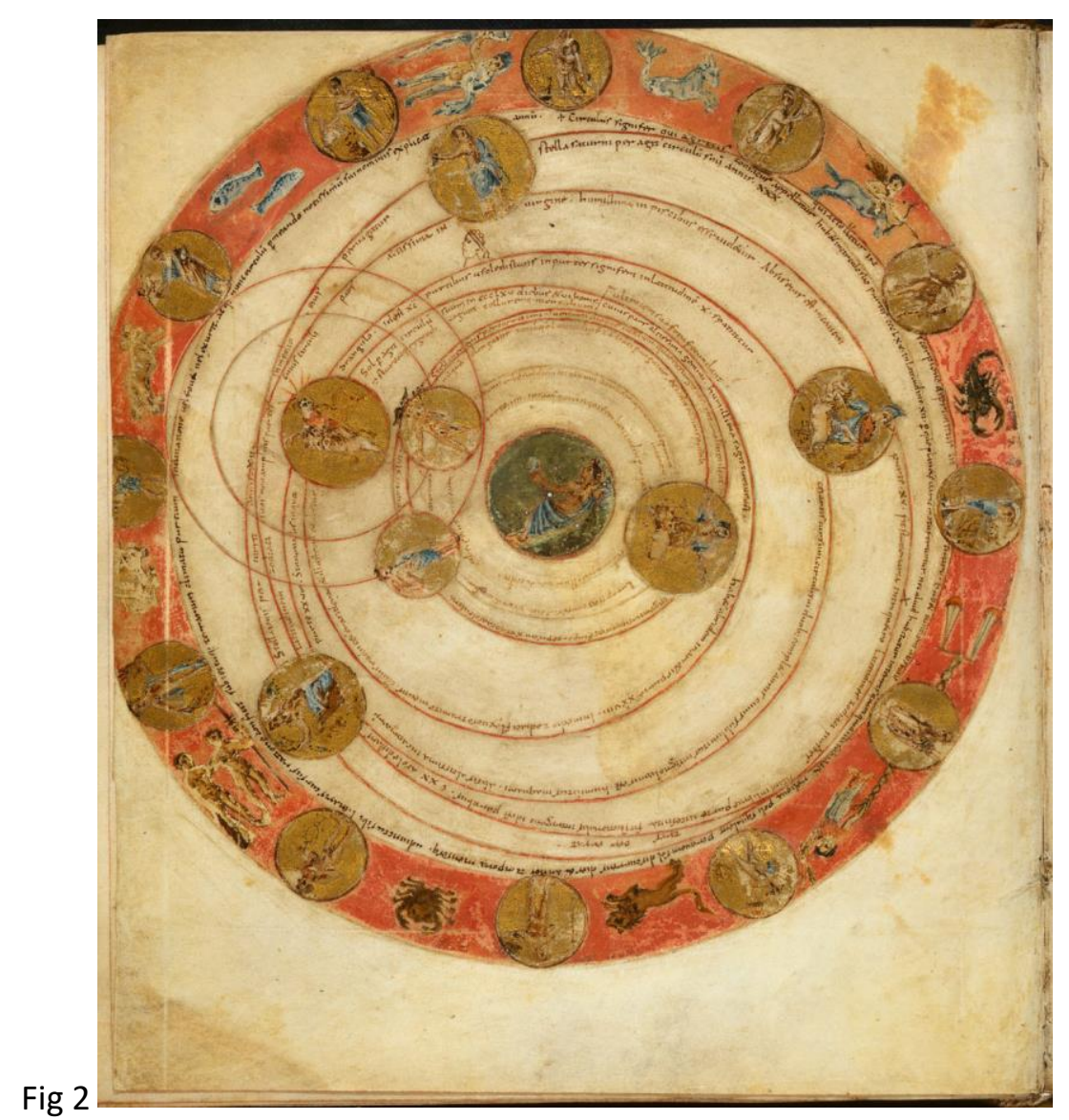


Fig 3

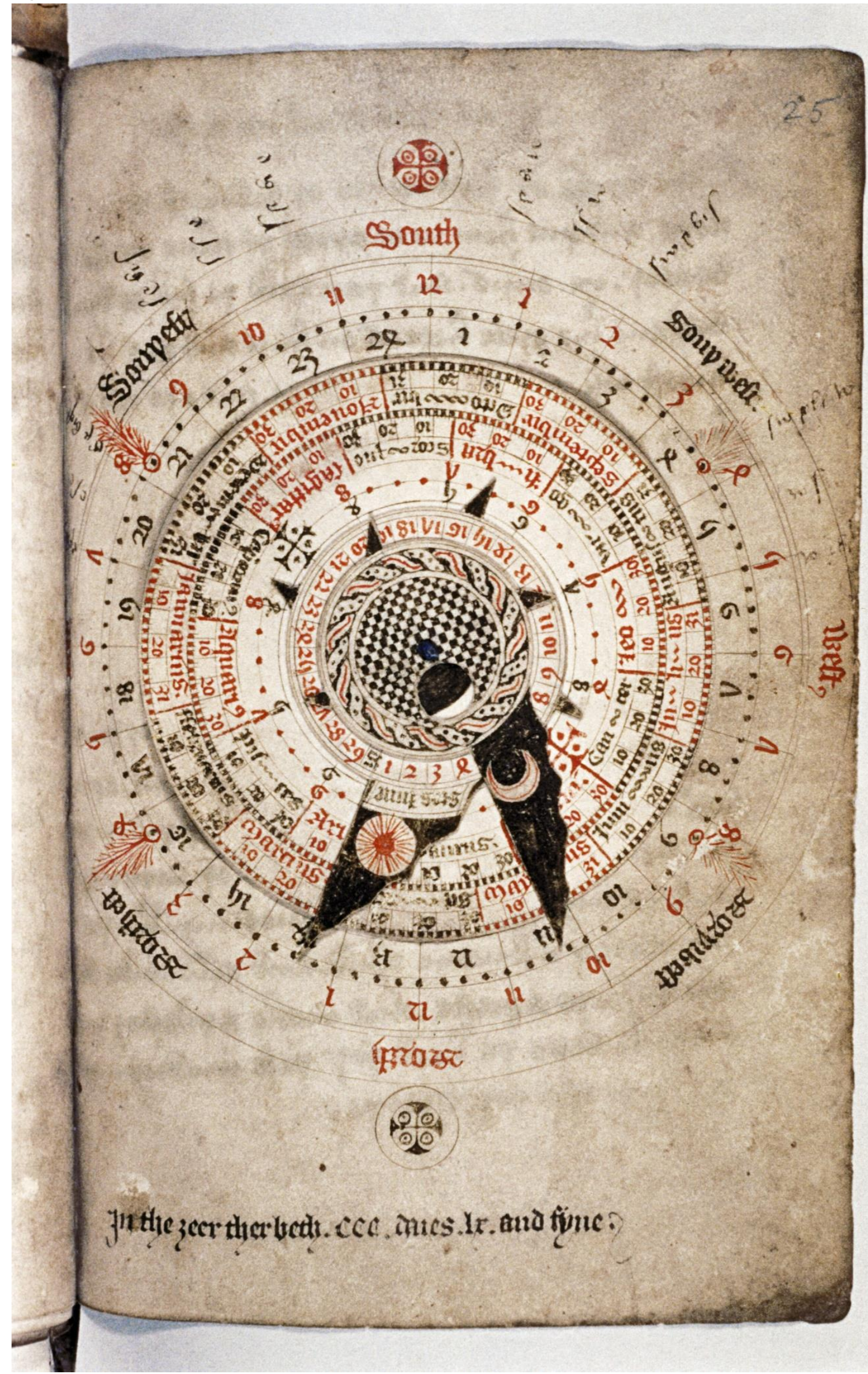




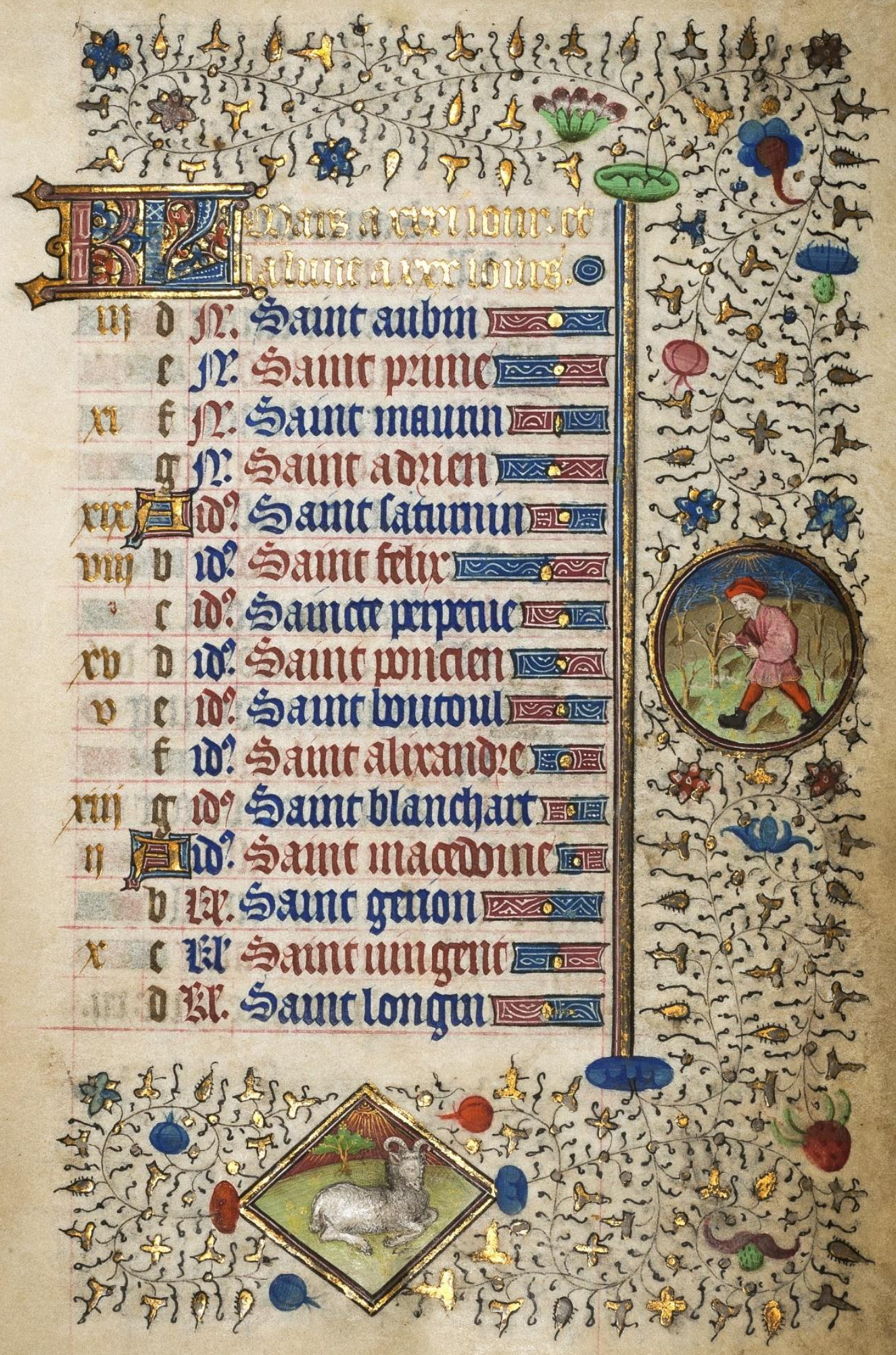




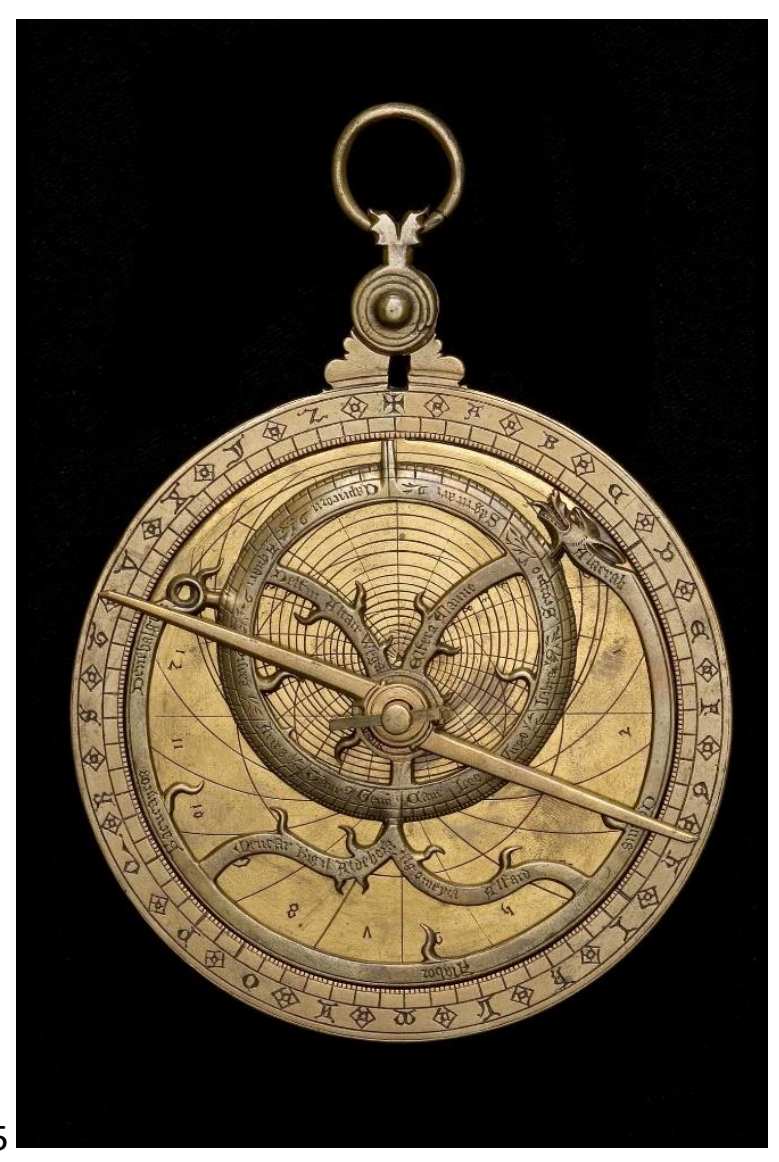




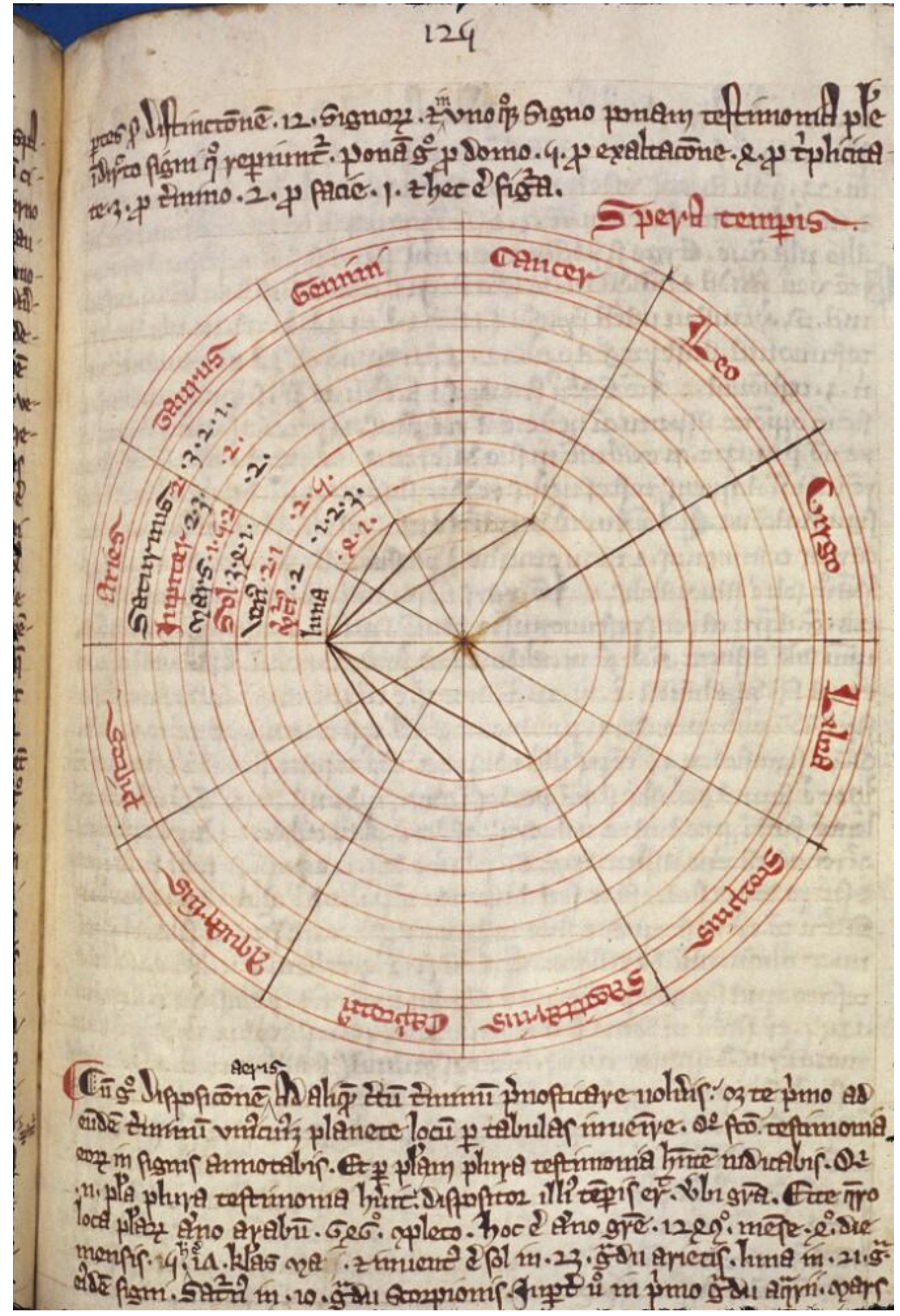




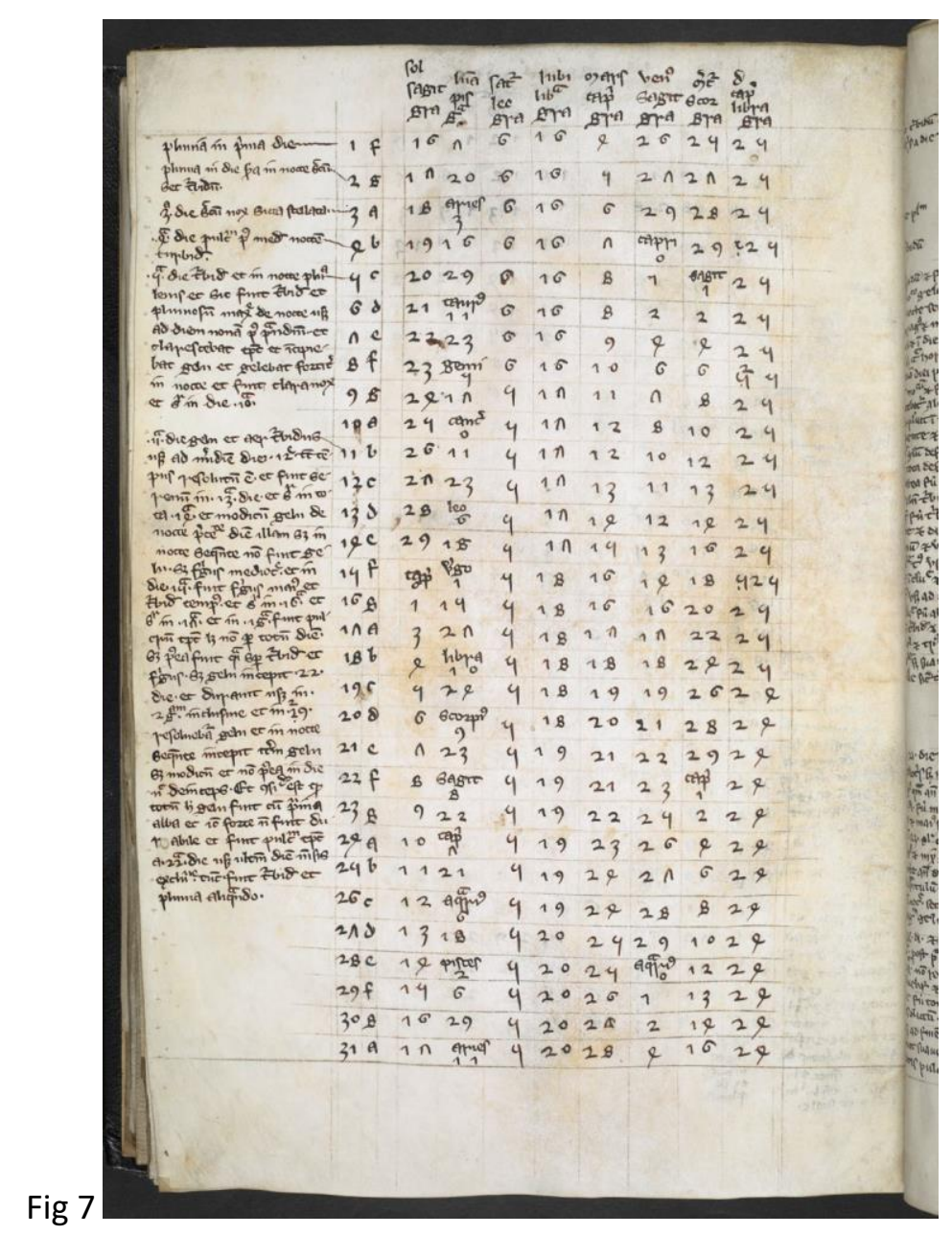


Fig 8

\section{Of OElober.}

Scoure Ditches, fet Plummes Peare, Apple, and Nut.

And now plafhe thou Trees, and let Hedges be cut.

To fow wheate and Rie to, thefeafon is good.

If fo much rayne fáll not, as doth make a flood.

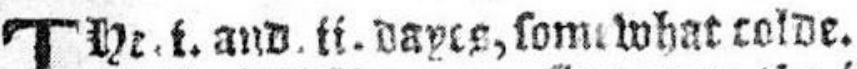

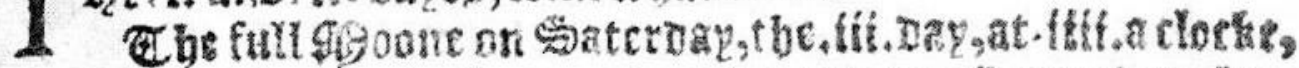

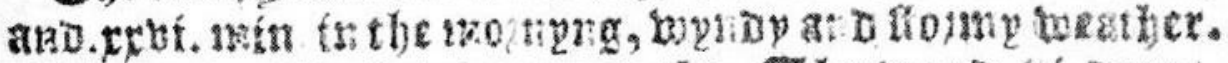

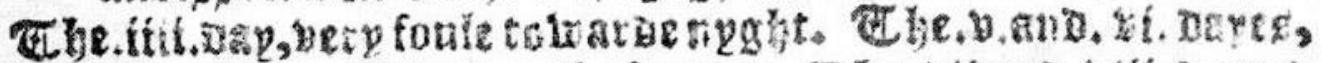

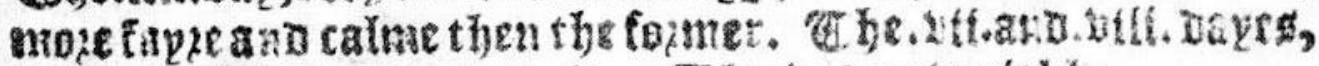

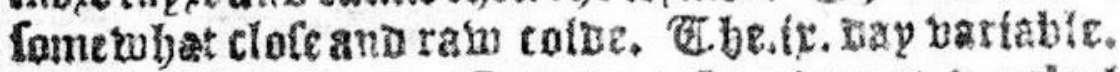

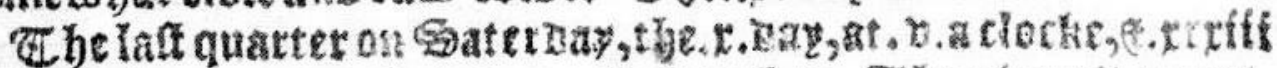

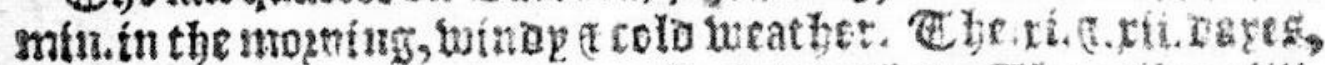

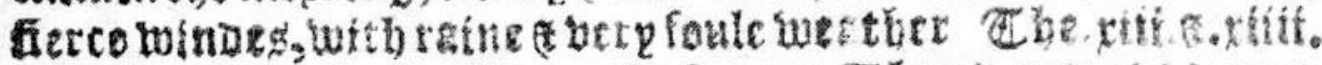

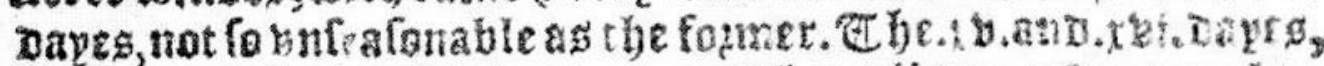

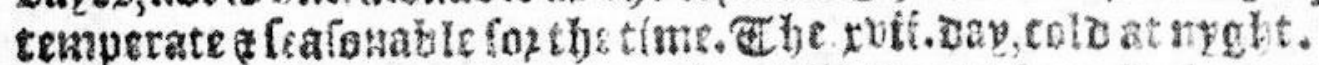

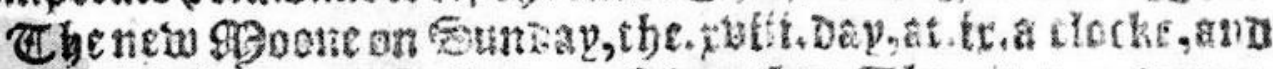

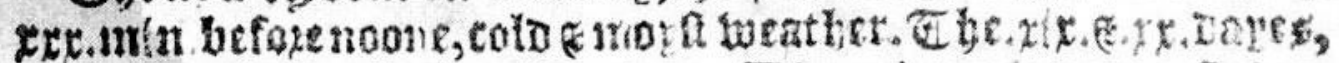

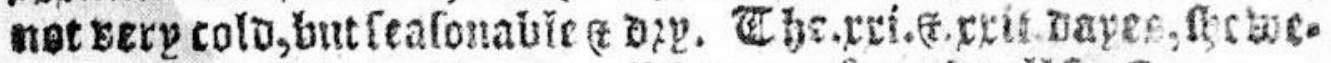

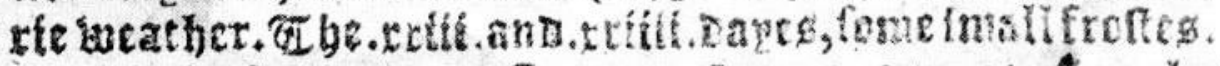

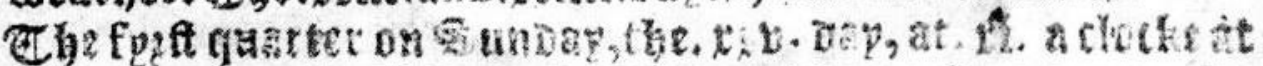

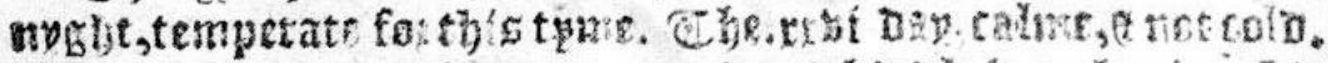

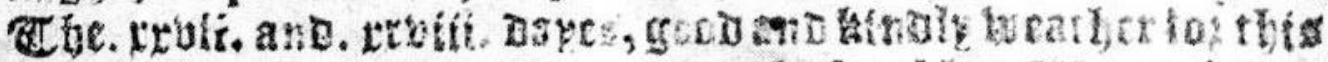

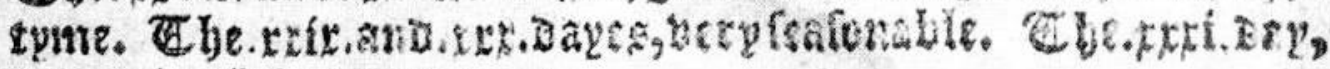

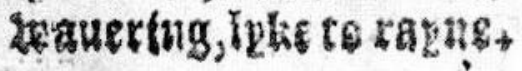

C. 椾

Of

Anne Lawrence-Mathers

University of Reading 